\title{
Proportionality as Fittingness: The Moral Dimension of Proportionality*
}

\begin{abstract}
George Letsas ${ }^{* *}$
Sheldon is grumpy about having to share his university office with his friend and colleague Raj, giving him a hard time. He reluctantly agrees to Raj having his own desk. As Sheldon tries to enter his office the following day, the door bangs against an object blocking it, an oversized antique wooden desk.
\end{abstract}

Sheldon [furious]: Why do you even want this here? Its size is completely disproportionate to its purpose.

Raj [laughing]: Well, seeing as its purpose was to piss you off, I'd say it's spot-on. ${ }^{1}$

\section{The Elusive Nature of Proportionality}

Proportionality pervades legal doctrine. It figures prominently in criminal law, where it speaks to questions such as the appropriate degree of the severity of punishment and the limits of using force in self-defence. It plays an important role in war law, qualifying principles of jus ad bellum and jus in bello. It is no less present in private law where it speaks to the mitigation doctrine and to the lawfulness of penalty clauses in the law of contract. But perhaps its lead role is to be found in constitutional law. In Europe and in other parts of the world, courts use

\footnotetext{
${ }^{*}$ This article is dedicated to the memory of Ioannis Mantouvalos.

** Professor of the Philosophy of Law, UCL. An earlier version of this paper was delivered as an inaugural professorial lecture at the UCL Faculty of Laws in 2016. Later versions were presented at the 'Human Rights and the Morality of Proportionality' conference held at Institute of State and Law of the Czech academy of Science in 2018 and at the Legal Philosophy Colloquium of the University of Zurich Law School. I am grateful to all the participants for their feedback. I have benefited enormously from discussions about this project with Nicos Alivizatos, Nicholas Hatzis, Jeff King, Dimitrios Kyritsis, Stuart Lakin, Matthias Mahlmann, Saladin Meckled-Garcia, Colm O’Cinneide, Massimo Renzo, Andrea Sangiovanni, Prince Saprai, Pavlos Sourlas, Malcolm Thoburn, Stavros Tsakyrakis, Dimitrios Tsarapatsanis and Emmanuel Voyiakis. I would particularly like to thank the editors, Jeff King and Kimberley Trapp, whose editorial patience and intellectual support far exceeded the call of duty. I am also extremely grateful to the two anonymous reviewers for the journal, who took the time to provide extensive penetrating comments and constructive criticisms.
}

${ }^{1}$ Big Bang Theory, Series 4, Episode 4, 'The Hot Troll Deviation'. 
it as a test for determining whether someone's fundamental rights have been violated. According to the orthodox understanding of proportionality within constitutional law, state interference with non-absolute rights (such as privacy, freedom of religion or expression) is lawful if, and only if, it is proportionate to a legitimate aim in pursuit of which the state must have acted. Since any part of the law in these jurisdictions can be challenged for violating fundamental rights, which enjoy a higher-order constitutional status, some scholars have gone as far as describing proportionality as a 'universal criterion of constitutionality'. ${ }^{2}$

Though proportionality no doubt matters in law, its moral dimension is elusive. It is often referred to as a principle, a reference that is elliptical since there is no moral principle to act proportionately tout court. An unqualified injunction to act proportionately will likely elicit the response: 'proportionately to what?' It is usually a specific type of action that one should take in proportion to a specific factor; one should use force in self-defence in proportion to the seriousness of the threat that the attacker poses; one should punish in proportion to the gravity of the wrong, and so on and so forth. ${ }^{3}$ Proportionality is a relational concept: it imposes a particular type of constraint on a particular type of action.

The way in which proportionality figures in law is a good indication that it tracks certain moral concerns. Other things being equal, it is immoral, and not just illegal, to kill someone because he was about to elbow me aside (and I knew that was all he was going to do). Likewise, it is immoral, and not just illegal, to sentence someone to life imprisonment for going through a red traffic light. In both cases we use the concept of proportionality to capture the moral impermissibility of the action. And it is worth noticing that proportionality here is the difference-maker as far as impermissibility is concerned. For punishing wrongdoers is, in principle, permissible and so is self-defence. Violations of proportionality make impermissible what would otherwise be permissible.

That the principle of proportionality has a moral dimension is also evidenced by the presence of disagreement. Philosophers and lawyers disagree about whether specific actions done in the context of specific practices are proportionate. In just war theory, there is disagreement about whether factors other than those that justify starting a war are relevant for judging the proportionality of going to war (ad bellum proportionality). For instance, whilst it

\footnotetext{
${ }^{2}$ DM Beatty, The Ultimate Rule of Law (OUP 2004) 162.

${ }^{3}$ Some concepts in the conceptual neighbourhood of proportionality appear to be non-relational. The ancient Greeks for example used a non-relational injunction, " $\mu \varepsilon \dot{\tau} \rho \circ v^{\alpha} \rho \iota \sigma \tau o v "$, which means 'everything in measure' or 'nothing in excess'. This injunction however falls - unsurprisingly given the Greeks' general moral outlook primarily within the domain of ethics, understood as one's own pursuit of the good life, as opposed to the domain of what is morally right and wrong by others.
} 
is impermissible to attack an innocent state solely to deter potential aggressors, is it nevertheless permissible to use more force against a country that has committed aggression than is required to stop it, in order to deter other aggressors? ${ }^{4}$ In law, courts disagree on what counts as a disproportionate interference with non-absolute rights. In the case of Hatton $v$ United Kingdom, the Grand Chamber of the European Court of Human Rights overturned the Chamber judgment which had found that the Heathrow airport's night flight scheme amounted to a disproportionate interference with the right to private life of a nearby resident. Such disagreements are not about matters of fact: theorists agree that a given a set of facts has obtained, yet disagree on their normative significance. In particular, they disagree about whether the act taken, within a given set of facts, is proportionate because they disagree about the factors to which that specific type of action (starting a war) should be proportionate.

Though the use of proportionality in law arguably has a moral dimension, it is not clear whether the same dimension is engaged in every legal doctrine that makes reference to proportionality. It is common for the same moral principle to figure in more than one area of law. For example, the moral principle that promises (or agreements) should be kept is the same in contract law, employment law and international treaty law. By contrast, the moral principle that one should punish in proportion to the gravity of the wrong appears to be different from the moral principle that one should use force in self-defence in proportion to the seriousness and imminence of the threat. The former is to do with the justifiability of punishing a wrong that has already been committed. The latter is to do with the justifiability of harming another person in order to prevent him from committing a wrong. We could say that both principles condition the permissibility of an action in the degree to which some further factor obtains (gravity of the wrong in punishment, imminence and seriousness of the threat in self-defence), but that is simply to reiterate the earlier conceptual point that the notion of proportionality is relational, relating a type of action to a specific factor. This point brings the two moral principles no closer than the fact they both include the definite article 'the'.

In this paper, I aim to explore the idea that the different uses of proportionality in law express the same moral concern, a concern that is self-standing in that it exists independently of the law. It is a possibility about which we might be skeptical at the outset. Proportionality in law appears indexed to concerns endemic in separate areas of law and the different moral

\footnotetext{
${ }^{4}$ See the disagreement between Jeff McMahan and Thomas Hurka on narrow and wide proportionality in jus ad bellum. J McMahan, 'Just Cause in War' (2005) 19(3) Ethics and International Affairs 1; T Hurka, 'Proportionality in the Morality of War' (2005) 33 Philosophy and Public Affairs 34. For a more recent discussion see F Kamm, Ethics for Enemies (OUP 2013) 119ff.
} 
values that they instantiate. That is not to say of course that there are no similarities or analogies. For instance, given that both the criminal law of self-defence and the international law of armed conflict concern the use of physical force, proportionality requirements in the former parallel those in the latter. ${ }^{5}$ In both cases we ask whether there are alternatives to using force and whether the force used will cause harm that far exceeds the harm prevented. But these similarities do not carry over to each and every instance in which law makes reference to proportionality. Law requires many actions to be proportionate and not just those that involve the use of physical force. For example, state interference with freedom of association or speech is governed by proportionality, and not all interference with freedom of association or speech involves the use of physical force. Consider for instance employment requirements to be a member of a trade union in order to exercise a particular profession, ${ }^{6}$ or not to be a member of an extremist political party. ${ }^{7}$ Such requirements interfere with fundamental rights without involving the use of physical force ${ }^{8}$ let alone force whose aim is to prevent imminent wrongful conduct. Moreover, knowing what counts as proportionate punishment does not seem to equip one with knowledge as to what counts as proportionate restriction of freedom of association.

It may well be the case that there is no moral dimension to proportionality if we detach it from the various contexts in which it figures. Perhaps proportionality is like a laundry list and there is nothing philosophically interesting we can say about what every item on the list has in common. Perhaps it is simply an umbrella term, or a trigger for a comprehensive moral assessment of a situation, not picking out any specific moral standard. But that remains to be seen. I should like to begin by moving away from the nuances of legal doctrine, so far as it is possible to do so, and explore first what proportionality means in non-legal contexts. If some moral concern underlies proportionality, it should have a life outside of legal doctrine. I take this to be a condition for an adequate account of proportionality.

\section{The Steam Hammer Conception}

\footnotetext{
5 As Tom Hurka observes in Hurka, 'Proportionality' (n 4) 38.

${ }^{6}$ Young, James and Webster v United Kingdom (1982) 4 EHRR 38.

${ }^{7}$ Redfearn v United Kingdom (2013) 57 EHRR 2.

${ }^{8}$ That is not to say that such requirements cannot be coercive. An action can be coercive even though it involves no physical force. See R Nozick, 'Coercion' in S Morgenbesser, P Suppes, and M White (eds), Philosophy, Science, and Method: Essays in Honor of Ernest Nagel (St Martin's Press 1969) 440-472. The fact that employment requirements may, downstream, implicate physical force by legal officials (eg court orders and bailiffs) does not change the fact that it is the proportionality of the requirement that is at issue, not the proportionality of the force exercised by legal officials.
} 
In mathematics and physics, we use the notion of proportionality to mean that there is a fixed ratio between two variable quantities, such that a change in one quantity always correlates to a change in the other. In mathematics, what fixes the constant ratio between two quantities is the truth of some theorem or axiom. Consider for example Thales's basic proportionality theorem. If you draw a line within a triangle parallel to one of its sides, then it will divide the other two sides in exactly the same ratio. Whatever is the ratio in which the drawn line will divide one side, it will be exactly the same for the other side. We can prove the truth of this theorem in a mathematical form, given what a triangle and a parallel line are. In physics on the other hand, what fixes the constant ratio between two variable quantities is the truth of some law of nature. For example, Newton's law of universal gravitation tells us that the force by which two objects attract each other is directly proportionate to their mass and indirectly proportionate to the distance between them. The bigger the objects, the more they attract each other. And the longer the distance between them, the less they attract each other. Newton's law is an empirical fact about the world. Knowing it helps us build bridges that hold up and fly planes that don't crash.

The above notion of proportionality however is descriptive; it figures in statements that tell us that two things in the world correlate as a matter of empirical facts. And the injunction to act proportionately is normative, not descriptive, stating that two elements ought to correlate. A normative use of proportionality is familiar within the field of aesthetics. We often say for instance that the size of an object should be proportionate to the size of its surroundings. Typically, large furniture makes small rooms look cramped and small furniture make large rooms look empty. We should note however that the appropriate aesthetic proportions between the sizes of the various objects are far from fixed. A large piece of furniture can define a small space, becoming a focal point, while a small piece of furniture can add depth and subtlety to a large space. To get the proportions right one needs to have good aesthetic judgment. Moreover, the two variables between which a proportionality relation should hold may belong to different aesthetic categories. In cinema, the pace of a film should be proportionate to its genre. Action movies are typically fast-paced and psychological thrillers typically have a slow build-up. But again, this is not an absolute rule. Some excellent psychological thrillers, like Tom Tykwer's Run Lola Run are fast-paced and some fine actionmovies, like Nicholas Winding Refn's Drive, are slow-paced.

Unlike descriptive notions of proportionality, aesthetic proportionality is a matter of exercising sound evaluative judgment in combining various aesthetic qualities that are 
pertinent, given the context. Of course, the fact that proportionality in aesthetics is normative does not mean that it has a moral dimension. A proportionately furnished room is beautiful, not moral and a disproportionately paced film is bad, not immoral.

Another well-known normative use of proportionality is to be found not too far away from law. There is a well-known definition given by a judge, which is not confined to law and seeks to capture its ordinary meaning. The House of Lords case of $R v$ Goldstein raised issues of proportionality under European Economic Community Law (as it then was). Lord Diplock noted the German origin of proportionality and felt that it needed an explanation in plain English. He said: 'in plain English it means that you must not use a steam hammer to crack a nut, if a nutcracker would do'. ${ }^{9}$ Lord Diplock's definition has been widely endorsed by lawyers but, as I will seek to explain, it assumes an understanding of proportionality that does not quite match the moral dimension of proportionality that I am seeking to elucidate here.

We should begin by observing that there is a missing premise in Lord Diplock's quote and it is that one is indifferent to how the nuts get cracked. For if one gets his kicks by watching steam hammers cracking nuts, then doing so is hardly disproportionate to one's ends. One of the reasons why using a steam hammer is disproportionate is that it is a mere means to an end of the acting agent, and not an end in itself. In other words, the notion of proportionality used here is linked to instrumental rationality, to the means one should use to advance one's ends, if she is to be rational. ${ }^{10}$ It involves, at first glance, comparing the cost of the various alternative means that are available, each of which suffices to bring about the intended outcome: from a nutcracker, to a normal hammer, to a steam hammer. And an action is proportionate if it is employing the least costly or onerous one, or-alternatively - if it is not employing the most costly or onerous one (which is different). Why spend time and money to get a steam hammer to crack a nut, when you have a nutcracker right there?

But a closer look at Lord Diplock's definition reveals that we are not just comparing the cost of different means. Time and money are finite resources and they can be used to serve other ends of the acting agent. Using a costly and time-consuming means to crack nuts places an opportunity cost on her other goals, for which there will now be less time and money. She will not, let us say, be able to watch her favourite opera this year. By contrast, if she were to use a standard nut-cracker she would be able to achieve both goals. So, proportionality here

\footnotetext{
${ }^{9} R v$ Goldstein [1983] 1 WLR 151 (HL ).

${ }^{10}$ Not all norms of instrumental rationality involve the notion of proportionality. It is irrational to employ means that cannot, or are extremely unlikely to, achieve a desired goal. Lawyers sometimes take the suitability of means to be part of a proportionality test, but outside the law this is misleading. Trying to crack a nut with a toothpick is futile and daft, but it is not disproportionate.
} 
involves an implicit assumption about the need to use available resources efficiently, with a view to maximize the pursuit of one's ends.

Suppose now that a nut is so tough that only a steam hammer will do. But if you hire a steam hammer, you will not be able to afford to, say pay your mortgage. So here you have to balance the benefit of eating a nut against the cost of not having a roof over one's head. If, as we should assume, the latter is far more important than the former, then getting a steam hammer to crack a nut would be deemed disproportionate, even if it is the only way to do it. So, Lord Diplock's conception also includes an element of cost-benefit balancing. What we are balancing are costs (including opportunity costs) and benefits to one's goals.

I shall call this, following Lord Diplock, the steam hammer conception of proportionality. It has these two elements (maximization and cost-benefit analysis) and it is inherently goal-oriented. It is, no doubt, popular both within and outside law. Yet despite its popularity it lacks a moral dimension. There is nothing morally untoward in employing means for achieving goals that on balance are ineffective or sub-optimal. I may be foolish trying to crack a nut with a toothpick or a steam hammer, but I do not act wrongly, nor do I violate anyone's moral rights. Likewise, many people pay a costly gym subscription every month, rather than pay per visit, even though they rarely use it. This might make them foolish and spendthrift, not to mention poorer, but not necessarily a wrongdoer. Other things being equal, the fact that an action is disproportionate to one's overall goals does not make it wrongful. Moral claims arise in the context of interactions with other people, not in the context of interactions with nuts and steam hammers.

The same point can be made by applying this concept of proportionality to impermissible acts. If one's goal is to violate other people's moral rights, then he gets no moral credit for using the most efficient means for achieving it. A torturer who has read Lord Diplock's quote and manages to crack his victim with minimal effort acts proportionately to his goal, but wrongly nevertheless. It is not that employing the most cost-effective means counterbalances the moral wrongness of torture, that he should be commended for his costbenefit calculation. Whatever it was that Lord Diplock translated into plain English, it was not the moral dimension of proportionality. This is not of course Lord Diplock's fault. The use of proportionality in non-moral contexts is perfectly sound. But for its moral dimension, we must look elsewhere.

\section{Utilitarianism and the Separateness of Persons}


There is a form of cost-benefit analysis with an inherent moral dimension, which is too familiar an idea in moral philosophy: the idea that an action is morally right if it maximizes the total sum of expected societal benefits minus the costs; it is wrongful if it fails to. Utilitarianism, in its many variants, makes this particular kind of cost-benefit analysis the only standard of rightness and wrongness. And whilst this is not the place to debate the merits of utilitarianism, we should nevertheless ask whether judgments of proportionality sit easily within a utilitarian framework. If they do, then the moral dimension of proportionality will be subsumed under the moral merits (such as they are) of utilitarianism. But if they do not, then that is a sufficient reason to look elsewhere for the moral dimension of proportionality.

Can an overtly utilitarian morality employ the notion of proportionality? The steam hammer conception of proportionality, seen in a utilitarian light, would become a tool for aggregate calculations of good and harm. We would no longer ask whether the benefit someone derives by cracking a nut is larger than the cost he himself incurs in hiring a steam hammer. On a utilitarian interpretation, the cost of the steam hammer would be born by all of us. We would be asking whether the benefit that an individual (or a group of individuals) will get from cracking a nut is larger than the benefits we would collectively derive, if we didn't pay for the cost of a steam hammer. Suppose that the cost of a steam hammer is equivalent to hundreds of nutcrackers, which nut lovers can use to quench their craving. Or suppose that it is equivalent to a medical device that can save hundreds of human lives. Using a steam hammer to crack a nut would then be deemed disproportionate, even if doing so is the most important thing in one's life.

Taking the steam hammer conception of proportionality to stand for calculations of aggregate utility will produce some counter-intuitive results, at least in the eyes of those with no utilitarian sympathies. The punishment of an innocent person would be proportionate if it maximizes utility, say by deterring crime and appeasing the public; aggressive war would be a proportionate form of state action if it maximizes utility, say by exterminating and deterring the evil dictators of the world; the banning of religion would be a proportionate restriction on freedom if it maximizes utility, say by eliminating the risk of large-scale atrocities committed by religious fanatics; and so on and so forth. Though most would find such results unacceptable, we should observe how ill-suited the concept of proportionality is to express the logic of utilitarian calculations. Recall that, in its central case, proportionality singles out specific actions and factors. It is the crime that punishment must fit, not the total sum of expected societal benefits minus the costs. Proportionality figures in statements about how 
specific moral duties within certain practices (e.g. punishment) take as their object specific constraints (that it fit the gravity of the wrong). Utilitarianism by contrast keeps the end to which any action must be proportionate fixed: the maximization of some notion of aggregate wellbeing. It is also meant to govern all human activity, as opposed to some, such as punishment or self-defence. A utilitarian reading of proportionality fails to fit the relational character of proportionality. Why would certain activities be subject to the principle of proportionality, understood as a utility calculation, when every action is subject to the principle of utility?

Here, we should observe that the relational aspect of proportionality indicates its deontological nature. A central tenet of deontological theories is that no amount of utility can render permissible actions (such as murder or torture) which are deemed wrongful regardless of their consequences. Punishing petty theft with life imprisonment, or killing someone in selfdefence against being elbowed aside, are likewise deemed impermissible regardless of the amount of utility that can be produced by such actions. The proportionality relation between the severity of punishment and the gravity of the wrong is not meant to track a calculation of utility. When the notion of proportionality is used in a first-person perspective, as in Lord Diplock's steam hammer quote, this deontological dimension is obscured. Conceivably, one's appetite for nuts should be proportionate to some factor such as one's needs or disposable income and so the relational character of the concept is seemingly preserved. But once the steam hammer conception, understood as utility calculation, is extended to society as a whole, then it can no longer account for the relational aspect of proportionality.

The extension of the steam hammer conception to interpersonal relations is another symptom of utilitarianism's inability to account for the separateness of persons. Utilitarianism takes norms of rational choice that apply to individuals (like the idea that one should not use a steam hammer to crack a nut) and extends them to society as a whole, making them a criterion of moral rightness: each one of us has a moral duty to maximize society's aggregate utility. It treats the ends of different people as if it were the same person, sacrificing ends of one person for the aggregate good. ${ }^{11}$ Direct forms of utilitarianism would be unable to explain why statements of proportionality typically identify very many different duties and correlate them with specific ends, regardless of whether utility is maximized. Indeed, utilitarianism would have to reject such statements as morally misguided.

11 This forms the basis of John Rawls's famous critique that utilitarianism ignores the separateness of persons. See J Rawls, A Theory of Justice (HUP 1971). 
Utilitarians might of course seek to offer an indirect justification for non-utilitarian rules of ordinary morality, including the idea of proportionality. They might say for example, as Jeremy Bentham did, ${ }^{12}$ that punishment proportionate to the crime is morally justified because, in the long run, it is more likely to maximize utility. The argument would be that if one factors in the long-term cost to utility of excessive punishing, then disproportionate punishment would be morally unjustified. This is a familiar manoeuvre in the utilitarian literature that however need not detain us much here. Like with other ordinary norms of morality, we would assert proportionality statements regardless of whether they happen to maximize utility in the long-run. In fact, we would do so even if we become convinced that say, punishing traffic offences with the death penalty will definitely maximize utility in the long-run. Indirect forms of utilitarianism by contrast would seek to explain away the moral dimension of proportionality, as derivative from long-term strategies to comply with the moral duty to maximize aggregate utility. They would seek to convince us that asserting proportionality statements irrespective of utility is a powerful conviction we have developed over time as a helpful decision-making process in seeking to maximize utility, but that it is really a sham, having no independent moral dimension. And though some may be convinced by such debunking arguments, the utilitarian hypothesis would eviscerate rather than vindicate the moral dimension of proportionality.

In sum, the issue is not (or not only) that a utilitarian account of proportionality will attract the familiar deontological objections. The steam hammer conception cannot even explain why killing a trespasser would count as proportionate form of self-defence in case it maximizes utility, say by deterring thousands of trespassers. There is nothing to which such a form of self-defence would be proportionate. ${ }^{13}$ Proportionality would have no place in our moral vocabulary if all action were aimed at maximizing utility. Utilitarian accounts of proportionality either reject it outright as a moral principle or explain it away as an indirect strategy to maximize utility. In both cases, they deny that it has an inherent moral dimension.

\section{Proportionality and Social Roles}

\footnotetext{
12 Jeremy Bentham, An Introduction to the Principles of Morals and Legislation (first published 1789, F Rosen ed, Clarendon Press 1996) chapter 14 ('Of the Proportion between Punishment and Offences').

${ }^{13}$ It is not an accident that so-called 'stand your ground' laws, which permit the use of lethal force in defence of even minor infringements of one's right to property, are defended on the basis that proportionality has no place in the law of self-defence. See H Hurd, 'Stand your ground' in C Coons and M Weber (eds), The Ethics of SelfDefense (OUP 2016) chapter 13.
} 
Many people around the world believe in the system of proportional representation, which advocates a specific correlation between votes and seats in parliament. In its simple form, proportional representation requires that the share of seats each political party has in parliament be the same as its share of the popular electoral vote. Proportional representation is not meant to express a law of physics or a mathematical theorem. It is an action-guiding normative statement about how we morally ought to conduct our politics, design our electoral process and allocate legislative power. It is a statement moreover whose truth depends, not on some empirical fact, but on a moral ideal, like democracy or citizenship.

The link between proportional representation and values of political morality, such as democracy, is complex and contentious. Democracy as a value calls for equal participation in collective governance. Proportional representation seeks to offer a conception of what it means to participate as an equal in democratic politics. Rival conceptions, such as the first-past-the post system, do the same. All conceptions presuppose that having elections and representative bodies is the right way to organize politics and that what makes it a right is the same political ideal, namely democracy. If proportional representation is justified, if it is the case that we ought to allocate seats in direct proportion to votes, it is because that is the best way to understand democracy. Put differently, it is moral facts about the value of democracy that - if at all-make relevant both the notion of proportionality and the two variable quantities (votes/seats) between which it should hold. But if some other system of representation (e.g. single transferable vote) captures the best conception of democracy, then the fact that it assigns parties a number of seats disproportionate to the number of votes would be of no normative significance.

The notion of proportionality, as it figures in the system of proportional representation, forms part of a contested conception of what we owe one another when, in our role as citizens, we distribute political power. The conception requires us to assign seats in proportion to popular vote. Applying this in practice requires no more than basic mathematics. All we have to do in order to find out how many seats a party is entitled to have following an election, is to multiply the number of votes it got by the total number of available seats and then divide the product by the total number of voters. The application of proportionality here is straightforward, since we are dealing with percentages of quantifiable variables (votes and seats). It is democracy, on the proposed hypothesis, that requires us to assign seats following the mathematical model of 1:1 ratio between the share of the votes and the share of seats. But the notion of proportionality employed here is indirectly moralized. Its application is mathematical because the correlatives are numbers and the ratio is fixed arithmetically. The 
moral dimension of proportional representation is derivative from the moral value of democracy.

Often however the concept of proportionality figures in interpersonal morality in a more direct way, requiring much more than resort to arithmetic. Consider the exchange in the epigraph between two friends, Raj and Sheldon, characters in the popular sitcom Big Bang Theory. Sheldon has been made to share his university office with Raj. But he hates the arrangement and makes Raj feel unwelcome and less worthy as an academic. When Sheldon reluctantly agrees for him to have his own desk, Raj decides to teach him a lesson by installing a huge desk, which takes up almost the entire space. Sheldon objects that the size of the desk is disproportionate to its purpose, to which Raj retorts that it is 'spot-on', given the reason for which he put it there.

There is a contrast here between two different senses of proportionality. Sheldon employs the steam hammer conception, complaining that the size of the desk is inefficient: the cost of having a big desk outweighs the benefit of its use. A smaller desk would have served Raj's goal equally well whilst freeing up more space for other goals, hence maximizing utility. Raj's response by contrast employs proportionality in its moral dimension. Sheldon had been a terrible friend and colleague, being unwilling to share his office with Raj. He made Raj feel unwelcome and unworthy as an academic, violating duties of friendship and collegiality that he owed towards him. Raj is arguably justified in having reactive attitudes of resentment and indignation towards Sheldon and Sheldon deserves to be at the receiving end of these attitudes. Putting an oversized desk in Sheldon's office is a way to express his frustration at Sheldon's failings as a friend. Raj's argument is that having a massive desk, and thereby creating an inconvenience, is a fitting way to express his indignation at his friend's mistreating him. He claims to be acting on a justified moral reason.

Note that the correlatives in this example are both moralized notions. To judge whether Raj responded proportionately we need to assess morally both the gravity of Sheldon's misbehaviour and the seriousness of Raj's joke on Sheldon. Had Sheldon tried his best to conceal his feelings of frustration at having to share his office, Raj's joke would perhaps have been a disproportionate reaction. Raj would have had to acknowledge it and would have had much less reason to feel indignation towards Sheldon. Raj's reaction would also have been disproportionate had he gone to the Dean of the faculty and filed a formal grievance against Sheldon. Though this could have been a justified reaction on his part if Sheldon was merely a colleague, that is not how friends behave. By contrast, a practical joke between friends seems to be 'spot-on'. Raj was arguably within his rights, as a friend and colleague, to react in this 
way. It was a reaction that befits his normative profile. What controls whether Raj's reaction was proportionate to Sheldon's misbehaving are assumptions we make about the nature of their relationship.

Nothing hangs of course on whether Raj was indeed justified in his reaction. The point of using the example is to highlight a non-legal manifestation of the moral dimension of proportionality and contrast it with the steam hammer conception. Proportionality here figures in the context of social relationships that are governed by moral values, such as friendship, and in which parties have abstract moral rights, duties and liabilities against one another.

Consider now another example from a familiar social practice. Suppose you invite me over for dinner. By accepting the invitation and by coming to your house my normative profile has changed. As a guest, I have special rights, duties and responsibilities towards the host. First, I now belong to the class of persons who have permission to be in your house. I am not a trespasser. Second, I acquire moral responsibilities towards you in relation to how I behave during my stay. These responsibilities include a number of issues, and proportionality is central to them. For instance, I should not overstay my welcome and spend a disproportionate amount of time at your place. If I do overstay my welcome, I violate duties I owe the host in my social role as a guest. Clearly, we would accept that the length of my stay as a dinner guest must be in proportion; but in proportion to what?

It might be suggested that the guest's duty is a matter of degree, that the more one stays, the more likely it is that one acts disproportionately. But that would be a mistake. If I am a close friend and I haven't seen you for a long while, it is right for me to stay for the whole day - that wouldn't be disproportionate. That is typical amongst close friends. But if I am a mere acquaintance and I stay for more than a couple of hours, then I risk acting disproportionately. The relation one has to the host is a morally relevant factor. It is one of the considerations that guests have to take into account, if they are to act proportionately.

Yet relationship to the host is just one amongst many relevant factors that determine what the guest's responsibilities are. A mere acquaintance may stay for the whole day too, if she is suddenly feeling unwell - that wouldn't be disproportionate either. An unexpected setback to a guest's health is a valid reason for guests to stay longer, making their stay proportionate. By contrast, other reasons guests might have to stay long are not relevant to how long they may stay - they are excluded or blocked. It is neither here nor there, if my favourite TV show is on and I want to stay and watch it. This is so even if my interest in watching TV is much stronger than the host's interest in having the dinner finish sooner rather than later. It is neither here nor there if I lost track of time and I would rather stay until the 
first morning train. In asking whether a guest's stay was proportionate, we are looking at the reasons guests act and then check if they fit their normative circumstances. The same length of stay may be proportionate in the case of one guest, but disproportionate in the case of others.

\section{A Fresh Start: Proportionality as Fittingness}

The previous section highlighted that judgments of proportionality often figure in contexts when one occupies a normative role (guest, colleague, citizen). We would not say that a thief spent a disproportionate amount of time in my house, that he overstayed his welcome, so to speak. ${ }^{14}$ Nor would we say that a housemate overstayed her welcome. She is on the lease, and she can spend however much time in the house she wants. She has no responsibility towards the dinner host in this respect and hence how much time she spends at home can be neither proportionate nor disproportionate. Her conduct in relation to the duration of time spent in the house, like the thief's, is not proportionality-apt. Moral questions about proportionate action arise typically within the context of a particular normative role one occupies. They are to do with whether an action fits the normative role that the agent occupies. I shall call this notion of proportionality fittingness, to distinguish it from the steam hammer conception.

We should begin by noting that judgments of proportionality usually apply to the actions that are in principle morally permissible. By this I mean that one has permission or standing to interfere with another's sphere of liberty. Citizens have standing over how electoral votes correlate with seats in representative bodies. Guests have permission to enter the host's property and that distinguishes them from trespassers. By contrast, murder, theft, torture are not disproportionate ways to act - they are just wrong. The mere acquaintance's staying for the whole day is disproportionate, because it could in principle have been possible for it to be permissible - say if the guest were a close friend or had unexpectedly fallen ill. But a guest's pretending to leave and hiding in the basement, or deliberately locking himself in the bathroom, does not make his stay disproportionate. It is neither proportionate, nor disproportionate - it is a separate wrong (trespass) that is always impermissible and, just like assaulting or stealing, could never be a justified way to behave, not only as a guest but in general.

\footnotetext{
${ }^{14}$ The thief however might say, using the steam hammer notion of proportionality, that he spent a disproportionate amount of time in the house and he ended up being caught by the police.
} 
Proportionality as fittingness differs from the steam hammer conception of proportionality, in that it is not about a cost-benefit analysis of the effect of an action on the overall goals of the acting agent (or of anyone else's for that matter). On the steam hammer conception, Raj's practical joke would be construed as serving a goal of his, say to teach Sheldon a lesson or to stop him from behaving callously. We would then have to balance not only the extent to which the joke achieved this goal but also the cost it had on Raj's other goals as well as the goals of others. Suppose the practical joke had no effect on Sheldon's callousness, who continued to be a terrible person with whom to share an office and did nothing to appease Raj's indignation. Or suppose that it made Sheldon more callous and angry, making things worse for both of them and the department as a whole. None of these considerations speak to whether Raj's joke was, as he put it, 'spot-on'. Raj's point is that his practical joke was entirely fitting, given the circumstances in which Sheldon put him. It was not a means through which he was seeking to achieve some further goal. The steam hammer conception is outcome-oriented; proportionality as fittingness is reason-oriented.

Consider now the case of a dinner guest who wants to stay longer in order to watch his favourite late-night TV show, which he will otherwise have to miss. Suppose that doing so will make him very happy, whereas it will only inflict a mild inconvenience on the host. In an aggregate cost-benefit calculation, more utility will be produced if the guest stays than if he leaves. Yet such calculation does not speak to whether the guest acts disproportionately. We would still say that the guest overstayed her welcome. Staying after the dinner is over, in order to watch TV, is not an appropriate way to behave as a guest. This is because the reason upon which the guest wishes to stay longer does not fit the role of a guest, as we conventionally understand it. ${ }^{15}$

The distinction between balancing the costs and benefits of an action on the one hand, and judging the appropriateness of the reasons for which one acted on the other, might be easily missed. This is because we often also refer to the latter exercise using the term 'balancing'. We might say for instance that in order to judge the proportionality of Raj's reaction we need to balance the type of wrong done to him by Sheldon, against the nature of his reaction. But saying so risks conflating an important distinction. Judging the relevance and

\footnotetext{
${ }^{15}$ I do not mean to suggest here that the idea of social roles is relativistic. Conventions enable us to comply with objective moral duties that exist independently of societal beliefs and practices. Though what a good friend is required to do might vary from place to place depending on people's expectations, the value of friendship (and of protecting reasonable expectations) is universal. I am grateful to an anonymous referee for raising this point. For a moralized account of conventions see G Letsas, 'The DNA of Conventions' (2014) 33 Law and Philosophy 535.
} 
pertinence of particular considerations vis-à-vis the role one occupies, is different from calculating the costs and benefits of an action to the interests of all affected parties. We might wish to call the former a 'weak' form balancing, to distinguish it from a cost-benefit calculation. But nothing hangs on the word 'balancing'. No-one will misunderstand the task of judging the appropriateness of a friend's reaction to a situation if the term 'balancing' is used.

I should here turn to what many legal scholars think is central to an account of proportionality, namely the idea of incommensurability. ${ }^{16}$ These scholars assume that proportionality is about balancing competing interests, but do not think that there is a single metric (such as happiness or preference satisfaction) by which to rank their value. All too often, they claim, it is not possible to compare two competing options that serve different interests: for example, take a walk in the park or have a cup of tea at home. ${ }^{17}$ It then makes no sense to ask whether one's action is proportionate, if by that we mean whether one has correctly calculated the overall costs and benefits of her options. On their view, there is no sense in which taking a walk in the park is more beneficial than having a cup of tea at home, no sense in which one may be criticized for taking a disproportionate number of walks compared to cups of tea. When this is the case, judgments of proportionality are deemed indeterminate by nature.

The view just described assumes that proportionality is about the balancing of interests but denies that such balancing is possible, because of the problem of incommensurability. It shares with the steam hammer conception the assumption that proportionality is about balancing different interests of well-being. The two accounts differ downstream, in that the steam hammer conception takes cost-benefit reasoning to be always possible whereas incommensurability-based accounts deny it. On the account proposed here, however, the problem of incommensurability is side-stepped. The moral dimension of proportionality does not lie in how competing goals of the acting agent can be weighed against one another. Rather, it concerns the question of whether one has acted on moral reasons that fit her normative role. The difference is not terminological. Consider the case of someone who likes to pinch his partner's cheeks, a habit he finds mildly annoying. As a form of self-defence when she attempts a pinch, her partner threatens to expose a lie that she has told at work. This would be a disproportionate reaction on his part and not because we have judged the harm to bodily

\footnotetext{
${ }^{16}$ See T Endicott, 'Proportionality and Incommensurability' in G Huscroft, BW Miller and G Webber (eds), Proportionality and the Rule of Law (CUP 2014).

${ }^{17}$ Joseph Raz's example from The Morality of Freedom (OUP 1986).
} 
integrity to be less valuable than the harm of exposing a lie. Neither the severity of the pinch, nor the seriousness of the lie, speak to whether it is fitting between partners to threaten to expose each other's lies. Even if, contrary to what the problem of incommensurability suggests, the lie paled in significance compared to the bodily harm caused by a strong pinch, we would still find the reaction disproportionate.

It may be objected here that the idea of proportionality as fittingness simply disregards the problem of incommensurability by changing the subject to a discussion of proper purposes or relevant considerations. ${ }^{18}$ Often, the objection goes, we need to judge whether the importance of a goal is sufficient to justify harming an important good, and this is the essence of proportionality. We need to judge for instance whether national security justifies deporting an illegal migrant at the cost of separating him from his family. This judgment however, the objection continues, is different from judging whether certain considerations are relevant in the course of pursuing a goal. To return to my previous example, it would be different if the question was whether one should expose his partner's lie at work (say a lie in her CV about her qualifications), in order to protect those who might suffer from it. In this case, it would seem that we need to balance the value of personal relationship against the goods that will be harmed by his partner's lie, such as her employer's business reputation or the safety of its customers. And the problem of incommensurability suggests that, outside a utilitarian framework, it might not be possible to balance these goods against one another.

The objection rests on the assumption that the essence of proportionality is about whether bringing about a sufficient amount of good can justify inflicting some harm, even if we do not assume a utilitarian framework. This assumption however is contestable. No doubt courts often talk like that, but we are here interested in the moral dimension of proportionality outside the law. To be sure, it is true that it might not always be possible to compare the value of two goods. It may not be possible to say for instance whether a rural lifestyle is worse, better or as good as an urban one. There are many different ways in which one may excel in pursuing the good life. But within a deontological framework the incommensurability of the good does not transfer over to questions about right and wrong. Deontologists define the right independently of the good and this entails that judgments of right and wrong do not directly track the goodness or badness of different choices. They are subject to the operation of some deontic notion such as fairness, justice, arbitrariness. In so far as proportionality has a deontological dimension, it cannot lie entirely in judging whether bringing about a sufficient

\footnotetext{
${ }^{18}$ I am grateful to an anonymous referee for the journal who raised this objection.
} 
amount of good can justify inflicting an amount of harm. Proportionality as fittingness aims at conceiving proportionality as a deontic notion and therefore rejects the assumption that it is essentially about balancing harms and goods. This does not mean that the goods involved in proportionality reasoning are deemed irrelevant. It means rather that the correct proportion between the various goods and harms involved will be determined by the social role in play, and the considerations that are relevant within it, rather than by the ethical value of those goods. For example, whether Raj's practical joke was proportionate to Sheldon's behaviour is ultimately a judgment about the normative role of a friend and the moral obligations that it comprises. It is not a judgment about whether Raj's goals are important enough to justify inflicting on Sheldon the inconvenience of an oversized desk.

According to proportionality as fittingness, every judgment about the proportionality between harms and goods is ultimately a judgment about the social role of the acting agent. So contrary to what the objection suggests, I am not attempting to change the subject to a discussion of proper purposes or relevant considerations. I am seeking to offer a deeper explanation of what goes on in judging whether it is permissible to effect a particular proportion of good and harm, an explanation that ultimately rests on what is a fitting or relevant consideration within the role one occupies. It is true that at surface level proportionality reasoning appears to involve the kind of balancing that the objection assumes and nothing more. If that were true then the problem of incommensurability would pose a serious challenge. Since proportionality as fittingness however is not hostage to this picture of balancing it can escape this challenge.

\section{The Attributes of Proportionality as Fittingness}

Here is the nerve of the moral dimension of proportionality: one has gone through a normative gateway, ${ }^{19}$ entering a distinct practice within which one has moral claims towards others in virtue of the normative role one occupies. Proportionality singles out the subset of considerations that properly fit that role, whilst judgments of proportionality concern what these considerations are and how they interact. Conduct undertaken within a particular role (say being someone's guest or friend) may be deemed disproportionate on the basis of more than one consideration. Guests may act disproportionately because they dominated dinner

\footnotetext{
${ }^{19}$ I borrow this label from AP Simester, 'Correcting Unjust Enrichments' (2010) 30 Oxford Journal of Legal Studies 589, 589.
} 
conversation, showing disrespect to others, or because they stayed late to save themselves the cab fare. One the other hand, not all considerations that may make the acting agent's action impermissible are tracked by proportionality. Houseguests still have duties not to torture, murder or steal. But actions that violate these duties are not proportionality-apt because they do not pertain to a particular role. Though one may act impermissibly without acting disproportionately, one may act disproportionately on the basis of a number of different considerations.

It is useful to unpack further the idea of a normative role. ${ }^{20}$ What does it mean to say that we acquire moral responsibilities in virtue of occupying a role? This is not just a metaphor. It conveys the idea that there are multiple levels of moral concern, each governed by separate moral principles. ${ }^{21} \mathrm{John}$ Rawls put this point as follows: 'the correct regulative principles for a thing depends on the nature of that thing'. ${ }^{22}$ It is not an accident that utilitarianism denies this pluralistic moral outlook. It is based instead on a monistic moral outlook according to which one and the same value governs all practices. Maximizing utility may make it right to punish an innocent person to life imprisonment. It is a moral principle that is relevant to all our practices and that determines exclusively what counts as morally just. Judgments of proportionality, by contrast, give content to the idea that different practices are governed by separate principles. Some distinctions are appropriate in some contexts but inappropriate in others. For example, the government acts unjustly when it distinguishes between rich and poor in apportioning criminal punishment. But it acts justly when it distinguishes between them in distributing taxation, healthcare or pensions.

Proportionality as fittingness has the following five attributes. First, it invites a judgment about the pertinence of a subset of moral considerations, which attach to the normative role that the acting agent occupies. The proportionality correlates are moralized elements, in the sense that their pertinence and connection to one another are determined by the moral values that govern the agent's normative role. One acts disproportionately in virtue of grounding her reaction on the wrong kind of reason, a reason that does not fit her role visà-vis another moral agent.

Second, only actions of the acting agent that are in principle permissible are proportionality-apt. Certain actions are morally wrong whatever the normative role of the

\footnotetext{
${ }^{20}$ On the general idea of obligations of role see M Hardimon, 'Role Obligations' (1994) 91 The Journal of Philosophy 333.

${ }^{21}$ Nagel puts it thus in 'The Problem of Global Justice' (2010) 33(2) Philosophy and Public Affairs 113, 122.

${ }^{22}$ Rawls (n 11) 25.
} 
acting agent, such as torture, murder or enslavement. That is not to say that a normative assessment of the reasons that govern one's role and circumstances never goes into what counts as torture or murder. ${ }^{23}$ A doctor feeding a person in a coma, following an accident, does not commit the act of torture. But a prison official force feeding a prisoner on a hunger strike does. To distinguish between the two, we need an account of the grounds upon which one may permissibly feed another person without their consent. The difference between the wrongs of torture and murder, as they are familiar from criminal law, and the wrong of acting disproportionately is not a difference in kind. Both track the reasons that govern one's circumstances. The difference is that what counts as the wrong of torture, or murder, does not normally vary depending on the normative role that the acting agent occupies.

Third, proportionality speaks to questions about the constitutive ingredients of pro tanto moral rights and duties within a normative role. Overstaying one's welcome is a wrong, but no doubt a very minor one. Sentencing someone to life imprisonment for a minor traffic offence by contrast is a serious injustice. But proportionality does not speak to the conditions under which pro tanto rights can be overridden. Suppose that a friend of mine will appear on the late-night TV show and I had promised her that I would watch the show. Suppose further that my promissory duty is weightier than my obligation towards the dinner host, not to overstay my welcome. All things considered, I am justified to stay longer at the dinner party. But this would not make my stay proportionate. I would have still overstayed my welcome, given that the conflicting promissory duty is external to the role of a guest. The proportionality correlates determine what counts as right and wrong within a normative role. It is not a measure by which we judge whether (what we have already assumed to be) a right may be overridden all things considered. The principle of proportionality leaves open whether a proportionate action may nevertheless be overridden by more weighty moral considerations; it does not speak to the part of morality that is concerned with overriding or defeating. An indefinite detention of a criminal suspect would not be made proportionate if it is necessary to prevent a nuclear catastrophe.

Fourth, unlike the steam hammer conception, proportionality in its moral dimension is not about a cost-benefit balancing of the means and ends of the acting agent. It is about the pertinence of, and interaction, between considerations that constitutively define a normative role (that of a friend, a guest, a parent, a judge etc.).

${ }^{23}$ See G Letsas, 'Reclaiming Proportionality: A Reply to Ripstein' (2017) 34(1) Journal of Applied Philosophy 24. 
Fifth, whether an action is disproportionate is not a matter of the degree to which some neutral quantifiable variable obtains, such as time. A parent who takes his eyes off his baby for a few minutes, while the baby is near a choking hazard, is neglectful. It is a disproportionate amount of time. But a parent who takes his eyes off his baby for 12 hours, while the baby is safe asleep in her cot, acts proportionately. Degrees of quantifiable variables matter to proportionality derivatively from the presence (or absence) of a pertinent moral consideration. We cannot even say, as a presumption, that larger degrees of a moral consideration pertinent to a role (e.g. time a parent spends with his child) are more likely to make the action disproportionate. If a parent is away from his child for several years because he has been kidnapped, then he acts neither proportionately nor disproportionately. His absence is not proportionality-apt because he is prevented from exercising the normative role of a parent. This entails further that applications of the principle of proportionality are inherently moralized and that there cannot be a morally neutral assessment of whether someone acted proportionately.

One may, at this point, worry that the moral dimension of proportionality as fittingness, as explained above, is still somewhat formal, lacking substantive guidance as to what it means to act proportionately in each and every practice. But I think we can say at least a couple of things of practical significance, particularly in relation to how the government ought to conduct its business.

The government goes through a number of normative gateways in carrying out its functions. It apportions various things (space, goods, resources, opportunities, risks) in various domains (punishment, employment, property, education) and under various background conditions (pre-existing law, standing expectations, practiced conventions etc.). What counts as disproportionate action within these domains depends on the moral considerations that are relevant within each. And though this means that our general theory of proportionality cannot offer a list of reasons that pertain to each and every normative role, we can still generalize across practices and suggest at least two ways in which it is likely to offend proportionality.

First, some considerations are very unlikely to be relevant to what the government does. These include suspect grounds, such as one's race, religion and sexual orientation. But they also include a number of other considerations such as one's political or philosophical beliefs, one's conception of the good life, one's lifestyle choices, one's traits of character, one's looks, one's genetic or biological condition, one's immigration status and many others. If the government acts on such considerations, it is very likely that it will act unjustly. And since such considerations could conceivably be relevant to what the government does (e.g. in 
cases of affirmative action, religious exemptions from general laws, and others), taking them into account when they are irrelevant will rightly count as disproportionate.

To be sure, when morally irrelevant facts relate to systematic or historical inegalitarian prejudices towards a particular class of people (e.g. those of a particular race, religion, sex or sexual orientation) we are used to calling the unjust treatment that takes them into account discriminatory rather than disproportionate. But the presence of such prejudiced motivations only adds to the injustice done to those people. If a teacher disciplines popular pupils more harshly than he does other pupils for the same offence, on the basis that this will have more of a deterrence effect, then he is doing them an injustice. One's popularity as a pupil is irrelevant to punishment. And if he punishes pupils more on the basis of their sexual orientation, then he is also doing them an injustice, for the same reason: one's sexual orientation is irrelevant to punishment. But the second injustice is worse, because - unlike the first - it is motivated by despicable prejudices that are known to have widely and systematically denied people what they are due. Discriminatory treatment on the basis of suspect grounds, is a seriously aggravated from of offending the moral dimension proportionality. We use the epithet 'discriminatory' to signify that it is a serious injustice, not to explain why it is an injustice. What proportionality as fittingness shows is that the normative roots of the wrongness of discrimination are the same as those of other fundamental wrongs. This has the advantage of explaining better why discrimination law and human rights law are not separate but overlap and intertwine.

Second, when one is occupying a role, she may endorse rules that prevent her from ever taking into account considerations that are relevant. Suppose the teacher practices a blanket rule, imposing a one-day suspension whenever a pupil misbehaves, without taking into account any other consideration such as provocation, repentance, the seriousness of the offence or the age of the pupils. If the teacher applies this rule, it is certain that she will act unjustly in many cases, in a way that does not fit her role as an educator. The moral dimension of proportionality rules such blanket rules out. And, as we shall see, it is not an accident that human rights courts find such blanket rules unlawful qua disproportionate.

\section{Proportionality as Fittingness: Criminal Law}


How does the idea of proportionality as fittingness play out in law? In this section, I explore how the conception of proportionality described above fares within two core areas of law: criminal and constitutional law.

One way to view the principle of proportionality within criminal law is as part and parcel of a retributive theory, according to which the point of punishment is to give wrongdoers what they deserve. Since they deserve to suffer for the wrong they committed, the severity of their punishment must be proportionate to the gravity of their wrongdoing. This understanding of proportionality however is too narrow. When coercing people with a view to censure their criminal wrongdoing, the government acts within a specific normative role. Most take for granted that the government may make certain forms of wrongdoing punishable by law. There are of course several conditions that must be met, such as publicizing criminal statutes and defining clearly the offences. But these conditions are insufficient to justify criminal punishment. Criminal authorities must stand in special relation to those whom they punish. To see this, consider cases where a state seeks to punish individuals who are neither its citizens nor its guests $;{ }^{24}$ Or consider the case of international criminal courts. ${ }^{25}$ In such cases the legitimacy of criminal punishment is in question precisely because a normative bond between the punishing agents and the wrongdoer is absent. There, only exceptional forms of justification for criminal punishment can work, if at all. ${ }^{26}$

By contrast, in standard cases of criminal prosecution and punishment, the justifiability of punishment will be shaped and informed by the relation that the institution bears with the defendant. In asking whether someone's criminal prosecution or punishment was proportionate we are asking whether the state has acted on reasons that fit that relation. States have institutions through which members of a political community relate to one another, typically as free and equal citizens. In exercising coercive force, state institutions are constrained by the various political values that pertain to liberal democracies such as equality, freedom and the rule of law. Criminal punishment is sensitive to those values. This is manifested in the fact that the proportionality of punishment does not track solely the gravity of the defendant's wrong. Many other factors speak to proportionate punishment or

\footnotetext{
${ }^{24}$ Consider for example the thorny issues raised in the case of Pitcairn island where the UK launched criminal prosecutions, even though the defendants did not in essence form part of the UK's political community; see D Oliver (ed), Justice, Legality and the Rule of Law: Lessons from the Pitcairn Prosecutions (OUP 2009).

${ }^{25}$ See the exchange between D Luban and A Duff in S Besson and J Tasioulas (eds), The Philosophy of International Law (OUP 2010) chapters 28 and 29.

${ }^{26}$ David Luban for instance argues that international criminal courts can 'bootstrap' themselves into legitimacy through the quality of justice they deliver. In Besson and Tasioulas (n 25) 591.
} 
prosecution. Some of them relate to the normative circumstances of the wrongdoer. It is relevant for instance whether the wrongdoer was a minor. Punishing a minor for committing a serious crime in the same way we punish an adult for the same wrong would be unjustified. ${ }^{27}$ The language of proportionality here is apt: it would be disproportionate to sentence a 10year-old murderer to life imprisonment. Likewise, it is relevant to the proportionality of punishment whether the wrongdoer was provoked by his victim, or whether she has repented. We should observe here that the baseline is set by how the state has treated other wrongdoers. A minor who is punished the same as an adult, for the same wrong, would still have grounds to complain even if the offence is punished lightly. The proportionality of punishment is partly determined by how the state has chosen to punish other wrongdoers, whose circumstances were similar. Making punishment insensitive to how other offenders are punished would run counter to the state's egalitarian duty to treat citizens with equal respect and concern.

Other aspects that are relevant to a proportionality assessment relate to the normative circumstances of the criminal authorities. In the case of Niemietz $v$ Germany, ${ }^{28}$ the authorities searched the office of Mr Niemietz seeking to find evidence with respect to the criminal offence of 'insulting behaviour' originating in an anonymous letter sent to a judge. The letter in question contained criticism of how the judge had handled the case of an atheist who had refused, on ethical grounds, to pay church tax. The authorities launched a prosecution, and used their legal powers to search Mr. Niemietz's premises, as a way to suppress a legitimate form of protest against the authorities and against church tax. The European Court of Human Rights found a violation of human rights on the basis that the search was disproportionate to the aims of preventing crime and protecting the honour of the judge. What made governmental conduct disproportionate was its reliance on reasons that do not fit its role as a democratic institution: using the criminal law to clamp down on expression that is critical of governmental officials is incompatible with that role.

Victor Tadros has defended a balancing conception of proportionality in the context of criminal law, which he contrasts with the idea of fittingness. He defines this conception as follows:

We do not judge whether punishment is proportionate by determining whether it is fitting. We judge whether it is proportionate by determining the level of harm that

\footnotetext{
${ }^{27}$ For an argument that the diminished criminal responsibility of minors relates directly to their lack of political participation in democratic decision-making see G Yaffe, The Age of Culpability (OUP 2018).

${ }^{28}$ Niemietz v Germany (1992) 16 EHRR 97.
} 
it is permissible to impose on offenders for the sake of the goods that punishment might bring about. We might call this proportionality balance. ${ }^{29}$

Tadros argues that the idea that it is wrong to punish offenders disproportionately does not rule out punishing people more than they deserve (and hence disproportionately), on the basis of other reasons. ${ }^{30}$ However, it seems to me a mistake think of the principle of proportionate punishment as setting upper or lower limits on how much we may punish offenders. Proportionality is only superficially concerned with limits, understood as quantities of a divisible entity (such as severity of punishment). While Tadros is right that considerations other than the gravity of the wrong may come into punishment, and call for more severe punishment, he is wrong to argue that such considerations are external to proportionality. If other reasons pertain to the role of the state as a censuring agent, then punishment that is grounded on those reasons is proportionate.

As noted already, the idea of proportionality as cost-benefit balancing lacks a moral dimension. Punishment is not merely a means to bring about some goal, even if that goal is morally worthy. For example, the question of whether the UK's ban on prisoner voting is proportionate punishment is not a question about whether the harm done to prisoners outweighs the goods that it brings about. The European Court of Human Rights found the ban to be disproportionate in virtue of its indiscriminate and automatic nature, not in virtue of some cost-benefit balancing. ${ }^{31}$ Nor is punishment necessarily a form of harm done to the interests of the offender, as Tadros assumes. Censuring need not involve harming the wrongdoer. Depriving offenders of the right to occupy certain offices, or to exercise certain rights, express a form of censure that may or may not harm the interests of the offender. Suppose that an offender who bounced a cheque never had any interest in voting in his life and will not be able to vote in the future, even if his interests change (say it is unlikely that he will live until the next elections). We can still ask whether depriving him of the right to vote is punishment proportionate to his wrong.

I do not of course mean to offer a complete theory of punishment here. The point is to study the structure of the idea of proportionality that underlies any plausible theory of justifying punishment. Just like the moral ideal of democracy serves as the organizing value underlying proportional representation, the moral notion of censuring wrongdoing serves as

\footnotetext{
${ }^{29}$ V Tadros, The Ends of Harm: The Moral Foundations of Criminal Law (OUP 2013) 36.

30 ibid, 333.

${ }^{31}$ See Hirst v United Kingdom (2006) 42 EHRR 41.
} 
the central justification for the requirement that punishment must be proportionate to the crime. Being central does not entail that the gravity of the wrong is the only pertinent consideration. The normative role of the state as a censuring agent is much more rich and complex than that. The richness and complexity are evidenced by the historical development of the idea of proportionate punishment and the moral progress that has occurred. In ancient forms of retributivism, the proportionality between crime and punishment was understood in terms of the lex talionis: the wrongdoer should suffer the same wrong that she committed - an eye for an eye. In modern forms of retributivism however such punishment is not only not deemed proportionate but is condemned as cruel and inhuman, out of place in the morality of punishment. Punishment nowadays takes a limited number of forms such as imprisonment, community service, fine, losing the legal right to exercise certain rights, or being banned from holding certain offices or jobs. This makes the mapping of the nature of a wrong onto the severity of punishment no small task.

Assessing the nature of a wrong is neither a mathematical nor a descriptive task, in the way that counting votes and seats is. It requires a moral judgment. Not only do we have to know what moral wrongs there are, and what they consist in, but we also have to assess their connection to a set of moral considerations that are pertinent to punishment. We have to justify the choice between different forms of punishment, decide for instance which wrongs are punishable by fine, which by a prison sentence, which by disenfranchisement and so on and so forth. All the elements in this equation are moralized notions. Asking whether punishment fits the crime is asking whether someone deserves to be treated in a particular way, given the normative role that the parties (punishing agent and wrongdoer) occupy. The obligations of their role may differ depending on whether it is the state or some other agent that occupies it (e.g. parents to children). We should preserve the idea of proportionality in punishment as a form of fittingness, by understanding it in the richer sense outlined in the previous section: it is a normative gateway that the government enters whenever it censures its citizens, occupying a distinctive normative role with special duties towards those against whom it wields its power.

\section{Proportionality as Fittingness and Fundamental Rights}


I would now like to turn to constitutional and human rights law. I mentioned earlier that proportionality figures there as part of a judicial test for determining whether the government has violated non-absolute individual rights, such freedom of expression, association, religion etc. In its standard doctrinal form, the test is said to consist of two main stages. First, courts will ask whether there has been an interference with a liberty or interest that falls within the scope of a right protected in the relevant convention or constitution (the scope or definitional stage). Second, courts will ask whether that interference was justified or "necessary in a democratic society' (the justification or limitation stage). The limitation will be deemed justified, if it was prescribed by law and was proportionate to a legitimate aim in pursuit of which the government acted.

On their face, the doctrinal labels suggest that the first stage of the orthodox test is about what rights we have and the second stage is about the conditions under which they can be limited. Courts tend to devote little time to the first stage of rights-based review which is about what falls within the protect scope of a human right ('the scope stage'), moving quickly to the limitation stage. In German constitutional theory, the test of proportionality is said to have three prongs:

(i) Is the impugned measure rationally connected to the pursuit of a legitimate aim (the 'suitability' test)?

(ii) Is the measure necessary for the pursuit of that aim (the 'necessity' test)?

(iii) Is the seriousness of the interference with the applicant's right proportionate to the benefits gained in pursuit of the legitimate aim in question ("proportionality in the narrow sense', or 'balancing')?

The first two prongs echo norms of instrumental rationality, as they figure in Lord Diplock's steam hammer conception. Without the third prong, they reflect ordinary judicial tests that are used outside the context of human rights review, such as the English test of Wednesbury unreasonableness, ${ }^{32}$ and that are not considered to be very stringent. The addition of the third prong (proportionality stricto sensu) is what is supposed to make the judicial test of proportionality more stringent. It appears to require an analysis of the costs and benefits of infringing someone's right across persons, not just from the point of view of the right-holder, and hence bears close resemblance to utilitarian calculations. Here is for example how judge

${ }^{32}$ Associated Provincial Picture Houses Ltd v Wednesbury Corporation [1948] 1 KB 223. 
Aharon Barak, a former judge of the Israeli Supreme Court, describes this part of the orthodox test in a book on proportionality:

The last test of proportionality is the "proportional result" or "proportionality stricto sensu" (Verhaltnismassigkeit im engeren Sinne)... [A]ccording to proportionality stricto sensu, in order to justify a limitation on a constitutional right, a proper relation ("proportional in the narrow sense of the term"), should exist between the benefits gained by fulfilling the purpose and the harm caused to the constitutional right from obtaining that purpose. This test requires a balancing of the benefits gained by the public and the harm caused to the constitutional right through the use of the means selected by law to obtain the proper purpose. Accordingly, this is a test balancing benefits and harm. ${ }^{33}$

So, we can say that the orthodox view of proportionality within human rights law consists in two main claims:

(1) Proportionality stricto sensu ('balancing') is a test that speaks to the limitation, rather than the content of rights (The Balancing Orthodoxy).

(2) Second, rights may justifiably be limited if the overall societal benefits of limiting them exceeds the cost of the harm done to the person whose right it is (The Maximizing Orthodoxy).

As evidenced by the label (Verhaltnismassigkeit im engeren Sinne), this orthodoxy originated in German constitutional theory and has received theoretical support in the work of the German constitutional scholar, Robert Alexy. ${ }^{34}$ It has been very influential in many jurisdictions (Europe, Canada, Israel, South Africa). According to the orthodoxy, proportionality does not offer an account of what rights you have; rather, it offers an account of how they can be taken away from you. Moreover, the orthodoxy offers a specific account of when rights may be justifiably limited: If the cost of interfering with someone's right is minor and the benefits to the collective good are huge, then the right may be infringed. But if the cost of interference is high, and the benefits to the collective good are minor, then the right

\footnotetext{
${ }^{33}$ A Barak, Proportionality (CUP 2012) 340.

${ }^{34}$ See R Alexy, A Theory of Constitutional Rights (OUP 2002); R Alexy, 'Constitutional Rights, Balancing and Rationality' (2003) 16 Ratio Juris 131; See also M Kumm, 'Institutionalizing Socratic Contestation, The Rationalist Human Rights Paradigm, Legitimate Authority and the Point of Judicial Review' (2007) 1(2) European Journal of Legal Studies 153.
} 
should be upheld. Barak's account, taken at face value, is squarely within the steam hammer conception, which-I have argued-has no moral dimension outside direct forms of utilitarianism. That the orthodoxy is wedded to the steam hammer conception is also evidenced by the fact that discussion of incommensurability dominates the literature of those skeptical of judges performing a proportionality test. ${ }^{35}$

It would appear, therefore, that the conception of proportionality outlined in this paper is out of place within human rights law. Recall that according to this conception proportionality (1) speaks to what pro tanto rights and duties one has in virtue of occupying a normative role, (2) is not about the conditions under which pro tanto rights may be overridden, and (3) is not about a cost-benefit calculation. The orthodox conception, by contrast, appears to conceive of proportionality as relating to defeaters of pro tanto rights and to condition defeat on the balancing of costs and benefits across people.

I have argued elsewhere, however, that the orthodox conception of proportionality does not fit the actual practice of human rights courts. ${ }^{36}$ Cost-benefit balancing is not an accurate description of what human rights courts actually do and hence incommensurabilitybased objections against judicial review are off the mark. True, courts often speak as if they are employing the steam hammer conception but the outcomes they reach cannot be justified under that conception. This should not surprise us since judicial tests employed by human rights courts are diagnostic institutional tools that help the courts structure their inquiry, which is moral in nature. ${ }^{37}$ Moreover, the idea of proportionality as fittingness can best explain judicial outcomes that would make little sense under the steam hammer conception. I will not here re-iterate my defence of this reading of the case-law, as my aim in this paper is to elucidate the moral dimension of proportionality and put forward a fittingness-based account, whether or not courts have already endorsed it. But I would like to add a few remarks regarding a fittingness-based account of proportionality within human rights law.

Any account which accords proportionality a moral dimension must accept that judicial interpretation of human rights will necessarily require resort to moral judgment. This will seem unpalatable to those who believe that it is not the role of courts to exercise moral

\footnotetext{
${ }^{35}$ See Endicott (n 16); F Urbina, A Critique of Proportionality and Balancing (CUP 2017).

${ }^{36}$ G Letsas 'Rescuing Proportionality' in R Cruft, SM Liao and M Renzo (eds), Philosophical Foundations of Human Rights (OUP 2014).

${ }^{37}$ For a defence of this view see G Letsas, 'The Scope and Balancing of Rights: Diagnostic or Constitutive?' in E Brems and J Gerards (eds), Shaping Rights in the ECHR (CUP 2014).
} 
judgment ${ }^{38}$ or those who believe that such judgment is required exceptionally, when law has 'run out'. ${ }^{39}$ Indeed, one could explain much of the skepticism towards proportionality in human rights law as premised on the idea that judgments of proportionality are either rulelike, and hence requiring no resort to moral judgment, or indeterminate, and hence unfit for judicial application. I have already addressed the issue of indeterminacy which is said to stem from the problem of incommensurability. But we must also point out that it is no objection to say that in applying proportionality human rights courts engage in moral judgment, unless one has already endorsed a variant of legal positivism, according to which legal judgment is different in nature to moral judgment. This issue, however, is contested territory in legal philosophy. ${ }^{40}$ To say that proportionality in human rights law is objectionable because it constitutes an 'open-ended' 41 moral judgment on the part of the judge is to beg the question against a non-positivist theory of law.

Nor should we evaluate how human rights courts apply the test of proportionality through the lens of the steam-hammer conception. In a scathing critique of the Hirst $v U K$ judgment of the ECtHR, John Finnis accused the Strasbourg court of being confused about proportionality. ${ }^{42}$ The UK government had argued that disenfranchising prisoners serves the 'intertwined legitimate aims of preventing crime and punishing offenders and enhancing civic responsibility and respect for the rule of law by depriving those who had breached the basic rules of society of the right to have a say in the way such rules were made for the duration of their sentence'. ${ }^{43}$ The Court accepted the legitimacy of these two aims, yet held that the blanket disenfranchisement of everyone who receives a prison sentence to be disproportionate. The Court noted that disenfranchisement is sometimes an appropriate criminal sanction (such as in the case of someone who has abused a public office or sought to overthrow democracy and the rule of law) but not always, and hence depriving every prisoner of the right to vote is disproportionate.

Finnis objects that the Court paid little or no attention to the aims of the UK's criminal justice system and that it silently substituted its own aim, which was to disenfranchise only

\footnotetext{
38 A view sometimes called 'ethical' or 'normative' positivism. See J Waldron, 'Normative (or Ethical) Positivism' in J Coleman (ed), Hart's Postscript: Essays on the Postscript to the Concept of Law (OUP 2001) chapter 12.

${ }^{39}$ See HLA Hart, The Concept of Law (2nd edn, OUP 1997) chapter 7.

${ }^{40}$ See R Dworkin, Law's Empire (HUP 1986).

${ }^{41}$ See Urbina (n 35).

42 J Finnis, 'Judicial Power: Past and Present' (Judicial Power Project, 20 October 2015) $<$ https://judicialpowerproject.org.uk/john-finnis-judicial-power-past-present-and-future/> accessed 2 November 2018.

${ }^{43}$ Hirst $v$ UK (n 36) [51].
} 
for a limited number of offences. It is not, however, clear what exactly his objection is. The Court accepted that forfeiting the right to vote is in principle compatible with the retributive aims of criminal punishment. But this means that not every wrongdoer deserves to lose their right to vote. The UK's policy however used the imposition of a prison sentence as a proxy for when disenfranchisement is a justified form of punishment. It left no discretion to the judiciary to judge whether disenfranchisement is appropriate given the nature and gravity of the offence. Suppose that someone committed a number of related offences, all of minor gravity, and received an aggregate prison sentence. In this case, disenfranchisement would be imposed automatically even though none of the individual offences might be serious enough to warrant losing the right to vote. Even if we assume that the length of prison sentences in the UK is typically proportionate to the gravity of the criminal offence they have committed, it does not follow that disenfranchisement should solely track the gravity of the offence. Disenfranchisement is an appropriate sanction for serious mala in se crimes against life and bodily integrity, such as murder and rape. But it is arguably also an appropriate sanction for electoral offences even though these do not normally carry a long prison sentence. By contrast, disenfranchisement would be an ill-fitting punishment for the offence of money laundering, even if it carries a long prison sentence. These are only some of the nuances over which the UK's automatic ban glides. ${ }^{44}$ Given the absence of any plausible rationale for disenfranchising prisoners automatically and indiscriminately, it is reasonable to view the ban as based on moralistic ideas about how to treat prisoners. The Court noted emphatically that

there is no question, therefore, that a prisoner forfeits his Convention rights merely because of his status as a person detained following conviction. Nor is there any place under the Convention system, where tolerance and broadmindedness are the acknowledged hallmarks of democratic society, for automatic disenfranchisement based purely on what might offend public opinion. ${ }^{45}$

In the terms of proportionality as fittingness, the Court can be seen as taking what might offend public opinion to be an ill-fitting consideration upon which to disenfranchise

\footnotetext{
44 An anonymous reviewer suggested that there are only two possible criticisms against Hirst: either disenfranchisement is never a permissible punishment or the UK's threshold (namely any prison sentence) is too low. Neither of these two criticisms however captures the fact that the length of a prison sentence is not a reliable criterion for the appropriateness of disenfranchisement.

${ }^{45}$ Hirst $v$ UK (n 36) [70].
} 
prisoners. ${ }^{46}$ It does not fit the values of tolerance and broadmindedness that govern the relations between citizens in a democracy. Perhaps Finnis thinks that challenging the automatic and indiscriminate nature of the UK ban has nothing to do with whether the UK has taken an effective means to pursuing the aims of its criminal justice system. But this would assume the steam hammer conception, according to which we are meant to balance the cost of employing a particular means against the benefits it brings to the pursuit of a given goal. The goal-based character of the steam hammer conception distorts the proper reading of Hirst as rejecting the appropriateness of the grounds upon which the UK's indiscriminate ban was based. Perhaps Finnis thinks that it is the role of legislature, not courts, to decide which grounds for criminal punishment are inappropriate. This position would need a separate argument as it would beg the question against the Court's argument to say that they acted as legislatures, not courts. After all, the Court was seeking to uphold the applicant's rights under the Convention, which is what it is legally mandated to do. And nothing about the principle of proportionality, understood as fittingness, makes the Court's reasoning confused or flawed. Finnis does not like the outcome in Hirst, and the role of human rights courts in general, but the Court's use of proportionality is neither confused nor arbitrary.

\section{Conclusion}

I have tried to show in this paper that proportionality has a moral dimension outside the life it leads within law. Its moral dimension has nothing to do with Lord Diplock's steam hammer conception. Proportionality judgments are not about cost-benefit balancing nor about the relationship between one's goals and the means employed to achieve them. The moral dimension of proportionality arises in the context of practices of interpersonal morality within which one occupies a distinct normative role. Proportionality tracks the reasons which fit the relationship between two moral agents and which in turn determine the appropriate proportions of harm and good. The second part of the paper sampled two areas of law in which proportionality figures prominently, criminal law and human rights law. It aimed to show that the moral dimension of proportionality as fittingness, advanced in the first part of paper, is suitable for law. Though there is great convergence between the moral and the legal dimension of proportionality, lawyers have so far done a poor job in articulating it. This is mainly because

\footnotetext{
${ }^{46}$ I do not mean to suggest that the Court in Hirst explicitly endorsed the analysis of proportionality offered here. My aim is to supply a normative basis for the outcome of the case, and the use of proportionality that underlies it, even if it differs somewhat from the Court's reasoning.
} 
the steam hammer conception has bedeviled theoretical inquiries into the nature of proportionality. It is time we put that metaphor aside and replaced it with the idea of proportionality as fittingness. 